A BILINGUAL TEXT

\title{
ENNI MAISAROH
}

Syahron Lubis

Sumarsih

Linguistik Terapan Bahasa Inggris Universitas Negeri Medan

Diterima Februari 2017; Disetujui April 2017; Dipublikasikan Juni 2017

\begin{abstract}
The research deals with translation shift in Garfield takes his licks a bilingual text. The objectives of the study were: (1) to find out the types of shifts in Garfield "Takes His Licks" a Bilingual Text, (2) to describe how the shifts occur in Garfield "Takes His Licks" a Bilingual Text, (3) to analyze the reasons why translation shifts occur in Garfield "Takes His Licks" a Bilingual Text. The research was conducted by using descriptive qualitative design. The data of this study were words, phrases, and clauses were translated from English into Indonesian. The data were collected through documentary technique. The technique of data analysis was interactive model. The findings of this study revealed that: (1) The category shifts in Garfield "Takes His Licks" a Bilingual Text are 1) structure shift, 2) class shift, 3) unit shift, 4) intra system shift, and 5) double types of shift. (2) There were some ways of translation shift used in Garfield "Takes His Licks" a Bilingual Text, namely grammatical change occurred, change in different word class, change in ranks and change in number. (3) There were four reasons of using translation shifts are (1) Different language systems, (2) Grammatical structures of SL do not exist in TL, (3) Literal translation is grammatically possible but may not accord with natural usage in the TL (naturalness between SL and TL) and (4) replacing virtual gap by grammatical structure.
\end{abstract}

Keywords: Structure Shift, Class Shift, Unit Shift, Intra System Shift.

How to Cite: Maisaroh, Enni (2017).

Translation Shift in Garfield "Takes His Licks" a Bilingual Text. Jurnal Linguistik Terapan 


\section{INTRODUCTION}

Translation is not a simple thing, but something that can be categorized as something complex. It is caused that translation cannot be separated from the various factor that relate to the linguistic and cultural factors. The complexity of the translation that has been confirmed by Hatim (2001:10) that "A translation work is a multi-faceted activity, it is not a simple matter of vocabulary and grammar only but that it can never be separated from the culture".

This implies the recognition that difference, rather than similarity, controls and influences translation process. Also in this perspective, the notion of a stable meaning has been challenged and dismantled. As a kind of communication, translation establishes an equivalent between the source language and target language. Translation is a complicated task, during which the meaning of the source language text should be conveyed to the target language readers. In other words, translation can be defined as encoding the meaning and form in the target language by means of decoded meaning and form of the source language is very close to our life nowadays. We can see and feel the advantages of translation for our daily life. The example is when we are watching television or reading books with different language. Actually, when we are watching or reading with different languages, we always do translation. Translation acts as a bridge of communication between people in all over the world. So, translations connect people in all over the world. Without translation, people of across cultural background cannot buld a communication well. Therefore, translation becomes important in every part of the world.

It can be seen that the translation activity has been crucial importance nowadays. The product of translation contains of information which is needed for science, education, and entertainment, such as comics, novels, newspapers, textbookss, and tabloids. It is elaborated by Bassnett explanation that translation has a crucial role to play in aiding understanding of an inceasingly fragmentary world (2002:1).

One of the results of translation can be seen in the comic bilingual text. Comic bilingual text has often been found as a smart pastime. Comic bilingual text is published because it gives benefit for students. Students who speak only in one language can learn about different languages and can pick up words in other languages by reading bilingual books. It can be seen that the use of bilingual text can be used as the way to serve the students the source language and target language in a comic bilingual text. Therefore, by reading comic bilingual text, students do not only get linguistic knowledge but also enrich the vocabulary how to translate source language to target language.

Translation is used to transfer the meaning of a text from the source language (SL) into the target language (TL). Basically, the text is reconstructed by translating the words from the SL into the 
$\mathrm{TL}$ and is arranged based on the structures of the sentence in the TL, therefore the structures are suitable with the TL and certainly there will be no loss of meaning.

There are several factors that should be remembered by translator in order to produce a good translation in translating a text. As Nababan (2003:26) states that there are two factors in translation they are linguistic factors that cover words, phrase, clauses, and sentences and extra-linguistic factors covering the socio-cultural on both source and the TL cultures.

Since translation is more than just transferring a text in the SL into an equivalent text in the TL, translation is not only translating each words or phrases from source language into the target languages. Therefore, it is important to point out that there are similarities as well as differences between English and Indonesian structure. When there are similarities exist, translation would be easy.

So, when there is different grammatical pattern, usually translating Indonesian into English is more difficult than from English into Indonesia. Therefore, the translators must consider some grammatical and lexical equivalent. In the translation activity, a translator tries to find the equivalent of source language text to target language text. The equivalent is the correspond content of the message of SL text to TL text. It is the first step that a translator finds in translation. So, formal correspondence is the equivalence of structures both the source language text and the target language text that denied (equivalent over formal correspondence).

Each language has its own characteristics or even distinction. Therefore, the translation from the SL into the TL cannot be exact equivalents as both languages are widely different in structure and cultural background. The understanding of the structure and the culture in both languages are required by the translator as it makes the translator capable of grasping the meaning in the text accurately and allows transferrring the same meaning. As Vinay and Dalbernet (1995:34) states that equivalence refers to cases where languages describe the same situation by the different stylistic or structural means. Meanwhile, the form in the SL has a new form or different form the TL; it is called a shift. According to Catford (1965:73) a shift is the departure from formal correspondence in the process of going from the SL to the TL. It represents some changes occurring in a translation process, the element of the TL commensurate with the SL is always used by the translator in order to express the same message in the target text. Since every language has its own rules, differences in these rules will cause a shift.

Shift is one of the implemented ways by the translator to create an equivalence translation toward a source language. It is done by changing the class of word such as verb is translated into noun, by changing the class of word into phrase such as verb is translated into noun, by changing the class of word into phrase such as verb is translated into verb phrase, by changing class of word into compound word and so on. Based on the researcher's previous mentioned shifts, then Catford 
(1965:73) states there are two types of shift. Those are category and level shift. Category shift is divided into four subdivisions; they are structure, class, unit and intra-system shift.

Based on the shifting of structure concept, there is a basic technique to solve the problem in shifting of the translation, that is translation shift, the placement of one grammatical unit by another. For example: A pair of trousers translated into sebuah celana. Here there is transposition that a change happens from plural noun into singular noun. Transposition is the only translation procedure concerned with grammatical. In translating text from source language into target language, transposition is main process in the translation that should be taken into account by translator.

The translator transfers the message that the author intended. In the process of translating, there are some challenges that the translator may encounter. The translator should consider the reading level of the reader when translating literary works, especially in translating children's literature. Moreover the important thing is the translator deals with two different language system between source language (SL) and target language (TL). Consequently, shift cannot be avoided when establishing translation equivalence between two different language systems, which is going to be the main analysis in this thesis. The matters of shifts sometimes occur in the process of translation and the form of the message is acceptable because of translation equivalence.

In line with the shift problems, the researcher is interested in conducting a research to analyze the result of the translation between two languages, from English into Indonesian in Garfield "Takes his Licks" comic bilingual texts. It is fruitful to the people who study translation, especially for the college students who are majoring English Program. They need to know the comparison between English and its translation into Indonesian. The translation problem is the matter of rendering the lexical, semantic or pragmatic from source language into target language. In translating the texts of English into Indonesian it's frequently found various obstacles caused by unavailable vocabulary in the target language to accommodate words and meanings in source language (English) as well as system differences in both languages. It can be seen in many English comics that have been translated into Bahasa Indonesia. One of them is Garfield "Takes his Licks" written by Jim Davis. This comic was translated into the title, DijilatKenyang by Suryanto and published by Nexx Media.

This kind of comic is a form of entertainment which some people like. This is due to the fact that reading comics are enjoyable and entertaining. Most people enjoy fictional stories whether in the form of comics or novels. The majority Indonesian people do not speak and understand English. Therefore, in order to make the reader still can enjoy the comics, translation is needed to overcome this language barrier. So comics are translated into Bahasa Indonesia.

By reading non-scientific books, the reader can see how people in other parts of the world behave. Besides, these stories can expand the imagination of the reader to look back into the past. In addition, reading non-scientific books sometimes give more fun and the experience to the reader. Reading comics is a good pastime or recreation. It is relaxing and one can escape from one's life and 
its problems temporarily as one gets involved in the lives of the characters in the comic. Nowadays, there are lots of scientific and non-scientific books are translated into many languages. Many literary works, including comics, have been translated from English into Indonesian.

The researcher found the shift in translation of Garfield bilingual texts "Takes his Licks" which is translated into Indonesian "Kenyangdijilat" as seen in the following preliminary data.

Based on preliminary data, translation shift in Garfield "Takes His Licks" a Bilingual Text can be seen as dollows:

SL : Just when you think they have televised every sport.

TL : Saatkaupikirsetiapjenisolah raga sudahpernahtampil di TV.

Based on the translation above, the word "televised" is translated into tampil di TV categorized into unit shift. It can be seen that in SL "televised" change in ranks when translated into target language "tampil di $\mathbf{T V}$ ", one unit translated into three units, downward ranks. It means that the unit shift is a number of units from the low and the high one. So the unit shift was shown as between SL televised, downward into upward rank shift. Unit shift occurred to replace virtual lexical gap by a grammatical structure, such as the change from phrase to clause as the word "televised" to phrase "tampil di TV".

Another data of translation shift can be seen as follows:

\section{SL : Gimme a G}

TL : Ada G

Based on the translation above, the word "give" in source language is translated into "ada" in target language. The verb "give" in source language is changed into adjective in target language “ada". Then, it's called as class shift, the changing of verb in source language into adjective in target language. A source language item was translated in a target language item which belongs to a different grammatical class. It occurs where literal translation is grammatically possible but may not accord with natural usage in the TL so it is the matter of naturalness between SL and TL.

Different types of shift are found as follows:

SL : I wonder if other people's pets have wild mood swings?

TL : Perubahan suasana hati hewan peliharaan orang lain ekstrim seperti ini apa tidak ya?

Based on the translation above, the phrase "people's pets" is translated into "hewan peliharaaan orang". In this case, the source language "people's pets" is not translated into plural form, but in singular form "hewan peliharaan orang", not "hewan-hewan peliharaan orangorang". It should be in the plural form, but the translator makes it single form in the target language. Even, it is still equivalent but lexicon is shifting in translation. It is worth nothing here that the translator is compelled to be bound by the SL writer's choice. In cases where compatible terms with the source system are taking place in the target system, the translator has to bridge the gap by using 
some means. For instance, of the system is to describe a singular or plural noun. And it's categorized as intra system shift.

And the example of structure shift can be seen as follow:

SL : It says here people with pets live longer

TL : Disini dikatakan, pemelihara binatang hidup lebih lama

Based on the translation above, the clause "it says"is translated into "di sini dikatakan". It can be seen that the clause "it says" is not translated into active voice "mengatakan" but it is translated into passive voice "dikatakan". In this case, the structure shift occurred, which was marked by the changing of active into passive voice.

Based on the translation above, it could be seen that the translation shifts occur in Garfield "Takes his Licks" a Bilingual Text. There were four category shifts, namely: structure shift, class shift, unit shift, and intra-system shift. Dealing with the explanation above, the researcher is interested in analyzing the result of translation in Garfield bilingual text which is written in two languages, English and Indonesian.

This research would like to investigate the types of shifts in Garfield "Takes his Licks" a bilingual text, to describe how the shifts occur in Garfield "Takes his Licks" a bilingual text and to analyze the reason why translation shifts occur in Garfield "Takes his Licks" a bilingual text.

\section{RESEARCH METHODOLOGY}

A research design is to suggest otherwise would be misleading. How the researchers proceed is based on theoretical assumptions (that meaning and process are crucial in understanding human behavior, that descriptive data are what is important to collect, and that analysis is best done inductively), on data collection traditions (such as participant observation, unstructured interviewing, and documentation analysis) and on generally stated substantive questions. According to Bogdan\&Biklen (2007), data refers to rough materials researchers collect from the world they are studying, they are particulars that form the basis of analysis. Data include materials that people doing the study actively record, such as interview, transcripts, participant observation, and fieldnotes.

Here, the data of the study were words, phrases and clauses from Garfiled "Takes his Licks" comic (2006). The source of the data is Garfield "Takes His Licks" a Bilingual Text. Garfield consists of 681 texts as utterances and 62 pages both in the English source text and Indonesian target text. The author of the comic is Jim Davis, the translator is Suryanto and the publisher is Random House (Under Ballantine Books) Universal Occasionally Andrews McMeel Publishing, Indonesian 
publishing is Nexx Media Inc. Moloeng (2006:26) states that technique of collecting data is kind of documentary technique. It means that the data is one of the tool to bridge by reading document and examine include check it systematically. In analyzing the data, the researcher used Miles, Huberman and Saldana's technique (2014) which consisted of three steps, namely: data condensation, data display, and conclusion drawing and verification.

\section{FINDINGS AND DISCUSSIONS}

Based on the data display above, there were some findings found in this research, they were 1) there were four types of category shifts in translation shift occur in Garfield "Takes His Licks" a Bilingual Text from English into Indonesian, they are: Structure Shift, Class Shift, Unit Shift, and Intra-system Shift. Structure shifts are more dominant used. Structure shifts were used $66.2 \%$, unit shifts were used $18.2 \%$, class shifts were used $7.2 \%$, and intra system shifts were used $2.6 \%$. But in addition, there were some data categorized into Double Types of Shift about $2.6 \%$. It could be seen that TL shifted into both structure shift and class shift, TL shifted into both structure shift and unit shift, TL shifted into structure shift and intra system shift, and also TL shifted into unit shift and class shift.

There were some ways of translation shift used in Garfield "Takes His Licks" a Bilingual Text, namely grammatical shift occurred, SL was translated into grammatical class (such as an adjective was translated into a verb, a verb shifted into a noun, a noun can be translated into verb), SL was changed in the ranks, and the plural term was translated into singular.

There were four reasons behind the occurrence of shifts that used in Garfield "Takes His Licks" a Bilingual Text. The first was when SL and TL have different language systems that the shifts occurred automatically and translators have no option but to undergo those shifts as in the translation of English plural words to Indonesian singular words and the position of adjectives. Another reason is when the grammatical structures of SL do not exist in TL, for example the initial position of verb in Indonesian sentences. Further, shifts also occur where literal translation is grammatically possible but may not accord with natural usage in the TL that it is the matter of naturalness between SL and TL, for example the change of word class from adjective to verb. The last, shifts occur to replace virtual lexical gap by a grammatical structure, for example the change from phrase to clause.

\section{DISCUSSION}

After analyzing the data and referring to the research findings, there are some points that are considered to be discussed as the important ones. Those are as the following: 
As proposed by Catford (1965: 73), 'shift' is the departure from formal correspondence in the process of going from SL to TL. Shifts occur when the source language text is translated into different grammatical or phonological form in the target language text. While formal correspondence is any grammatical category in the target language which can be said to occupy the same position in the system of the target language as the given source language category in the source language system (Machali, 1998:13). Shifts in translation are known as those changes which occur or may occur in the process of translation, then the Garfied "Takes His Licks" a Bilingual Text also used translation shift.

The translation shifts by Catford (1965:73) divides into two categories, such as level shift and category shifts. The category shift is divided again into: (1) structure shifts, (2) unit shifts, (3) class shifts, and (4) intra system shifts. In structure shift there was any grammatical shift occurred to demand the language structure of the SL to TL. It could be seen the changing of active voice into passive voice, the changing of obligation structures modifier + head into head + modifier. In unit shift there was the changing of rank, that was departures from formal correspondence in which the translation equivalent of a unit at one rank in the source language is a unit at a different rank in the target language, downward into upward rank shift or upward into downward rank shift. In class shift there was a changing grammatical class of word, such as the changing of verb into adjective, the changing of possessive adjective into object pronoun, the changing of noun into verb. In intra system shift there was a changing of singular into plural and vice versa refers to the shifts that occurs internally, within the system, that is the for those cases where the source and the target language possess systems which approximately correspond formally as to their constitution, but when translation involves selection of a non-corresponding term in the target language system.

When the findings of this research were compared to another relevant research finding as in Dewi (2016), Dorri (2016), and Mobarakeh (2016), it was found that the dominant shift occurred was structure shift which was similar to the finding of this research. While in Rezvani (2014), Herman (2014) and Maasoum (2013) found that the dominant shift occurred was unit shift. The difference occurred because of the linguistics characteristics and features to convey a message, it has its own system and form. The four category shifts occurred in the ten researches including in Alzuhdy (2013), Banhegy (2013). Those were showed that shifts are inevitable some places in the translation process and they were because of different nature of language and variations that exist among them, so the translator was forced to deviate from the source text. Furthermore, Bahramy and Aidinlou (2014), they found that translation shifts can lead to finding some generalizations happened in the process of translation to create translated texts which enjoy higher quality in comparison with translated texts.

This study found that there were four types of category shifts of Translation Shift in Garfield "Takes His Licks" Bilingual Texts from English into Indonesian namely: Structure Shift, Class Shift, Unit Shift, and Intra-system in Garfield "Takes His Licks" a Bilingual Text, while the dominant is Structure Shift. It is similar to Catford's, this shift is the most common form of shifts and to involve 
mostly a shift in grammatical structure. In this case the structure shift involved a grammatical change between the structure modifier + head into head + modifier, the marker of the most difference between Indonesian and English.

This research is supported by the researches were conducted by Dewi (2016) in her paper,"Encouraging Students' Independency to Write trough the Analysis of English - Indonesian Translation Shift in the Luncheon", and Dorri (2016) in her paper, "The Application of Structure Shift in the Persian Translation". Based on the findings of the study, there was a statistically significant difference between SS and CS, US, and IS. The phenomenon of structural shift is a positive consequence of the translator's effort to establish equivalence between two different language systems, SL and TL. It is the occurrence of structural shifts that affects the translator's awareness of structural discrepancies between the SL and TL. In this sense, structural shifts which result from rearrangement, addition, omission, change of sentence tense can be defined as problem solving strategies adopted consciously by translators of literary texts may minimize the inevitable loss of meaning, through explicitation and compensation when rendering a text from SL into TL.

But in addition, this research found that there were some data categorized into Double Types of Shift. It could be seen that TL shifted into both structure shift and class shift, TL shifted into both structure shift and unit shift, TL shifted into structure shift and intra system shift, and also TL shifted into unit shift and class shift.

There were some processes of translation shift proposed by Catford (1965:73), shifts occurred at grammatical and lexical level, when there is no formal correspondence between two linguistics codes. The researcher found the process of translation shift in Garfield "Takes His Licks" a Bilingual Text.

The process of structure shift, it experienced by the target language when the source language was translated differently in the target language in arrangement of the word order and the obligation structure. It was the demand of the language structure of the SL to TL and it tended so much to the translator or the style of the certain translation due to the different ligustic system between SL and TL. The cases could be seen when the TL was translated from the active voice into passive one or vice versa. It was translated as like that because in order to make the TL is more natural and understandable by readers.

The process of class shift, it occurred when the translation equivalent of a source language item is a member of different class from the original item. There are eight word classes in English. They are noun, verb, adjective, adverb, preposition, pronoun, conjunction and determiner. The cases could be considered when a verb was translated into an adjective, possessive adjective may be translated into object, and adjective might be translated into verb. It could be seen that a source language item is translated with a target language item which belonged to a different grammatical class. 
The process of unit shift, the change of rank - that is, departures from formal correspondence in which the translation equivalent of a unit at one rank in the source language is a unit at a different rank in the target language. The rank of the language is started from the smallest one: word, phrase and clause. Grammatically, the shift occurred in target language in unit. It could be downward rank or upward rank.

The process of intra-system shift, it occurred internally within a system: that is for those cases where source language and target language possess systems which approximately correspond formally as to their constitution, but when translation involves selection of non corresponding term in the target language system. The case could be seen that source language indicated the plural by adding $-\mathrm{s}$ to the word, but target language has its own system to indicate plural noun by repeating the word.

With regard to the reasons of category shift in Garfield "Takes His Licks" a Bilingual Text from English into Indonesian based on Newmark (1988:85) which found that SL and TL have different language systems so the shifts occurred automatically and translators have no options but to undergo those shifts as in the translation of English plural words to Indonesian singular words and the position of adjectives. Another reason was because the grammatical structures of SL do not exist in TL. Further, shifts also occurred because the literal translation is grammatically possible but may not occur with the natural usage in the TL so it is the matter of naturalness between SL and TL, for example the change of word class from noun to verb. The last, shifts occurred because of replacing virtual lexical gap by a grammatical structure, for example the change from word to clause.

\section{CONCLUSIONS}

Based on the research findings, some conclusions were drawn that 1) There were four types of category shifts used in Garfield "Takes His Licks" Bilingual Texts from English into Indonesian namely: Structure Shift, Class Shift, Unit Shift, and Intra-system Shift. And there were some data categorized into Double Types of Shift. It could be seen that TL shifted into both structure shift and class shift. Also TL shifted into both structure shift and unit shift. 2) The ways of Translation Shift used in Garfield "Takes His Licks" a Bilingual Text, namely an adjective can be translated into noun, an adjective can be translated into verb, a possessive adjective into object. 3) The reasons behind the occurrence of shifts that used in Garfield "Takes His Licks" a Bilingual Texts based on Newmark (1988:85). The first one is when SL and TL have different language systems that the shifts occur and translators have no options but to undergo those shifts as in the translation of English plural words to Indonesian singular words and the position of adjectives. Another reason is when the grammatical structures of SL do not exist in TL, for example the initial position of verb in Indonesian sentences which is not familiar in English sentences except in imperative sentences. Further, shifts also occur where literal translation is grammatically. Furthermore, some suggestions were proposed for the 
linguist and practitioners that it is good to continue to examine and explore study relating to the particular linguistic in order to contribute developing the language science. For further researcher, it is suggested to conduct the research on others literature related to translation shift in order to obtain new findings. And for the authors, it is advisable to extend the matters contained literary value such translation shift that increasing the linguistic study and interesting to readers.

\section{REFERENCES}

Bahramy, M. \&Aidinlou, N.A. (2014). The Effect of Translation-Shifts Instruction on Translation Quality. Journal of Education and Practice.Vol. 5 No. 10.

Bogdan, R.C. \& Biklen, S. (1992). Qualitative Research for Education. Boston: Allyn and Bacon.

Catford, J.C. (1965). A linguisctic Theory of Translation. London: Oxford University Press.

Dewi, P. (2016). Encouraging Students' Independency to Write through the Analysis of English Indonesian Translation Shift in The Luncheon. https://jurnal.uns.ac.id/ictte/index. Vol. 2, No.1

Dorri, E. (2016). The Application of Structure Shift in the Persian Translation. Journal of Advances in English Language Teaching. Vol. 4, No. 1.

Hatim, B. and Munday, J. 2004. Translation: an Advanced Resource Book. London an New York: Routledge

Herman. 2014. Category Shifts in the English Translation of Harry Potter and the Philosopher's Stone Movie Subtitle into Indonesia. IOSR Journal of Humanities and Social Science. Vol. 19, No. 12.

Maasoum, S.M.H. \&Shahbaiki. (2013). Translation Shifts in the Persian Translation of a Tale of Two Cities by Charles Dickens.Academic Journal of Interdisciplinary Studies. Vol. 2, No. 1

Miles, M.B., Huberman\& A.M., Saldana, J. (2014). Qualitative Data Analysis: An Expanded sourcebook. Thousand Oaks, CA: Sage 
Miles, M.B., Huberman\& A.M., Saldana, J. (2014). Qualitative Data Analysis: A Sourcebook. Thousand Oaks, Calif: Sage

Mobarakeh, M.D. \& Sardareh, S.A. (2016). The Effect of Translation Shifts on the Level of Readability of two Persian Translations of Novel "1984” by George Orwell. International Journal of Humanities and Cultural Studies

Nababan. (2003). Teori Menerjemah Bahasa Inggris. Yogyakarta: PustakaPelajar

Newmark, P. (1988). A Textbook of Translation.New York: prentice Hall

Rezvani, R. \& Nouraey, P. (2014). A Comparative Study of Shifts in English Translations of The Qur'an: Case Study on "Yusuf" Chapter. Academic Journal of Humanities \& Social Sciences. Vol. 17, No. 1. 